\title{
University Students' Weekly Time Use and Its Influential Factors: A Case Study in China
}

\author{
Jingyao $\mathrm{Li}^{1}$, Shengchuan Zhao ${ }^{1, *}$, Junyi Zhang ${ }^{2}$ \\ ${ }^{1}$ School of Transportation and Logistics, Dalian University of Technology, Dalian, China \\ ${ }^{2}$ Graduate School for International Development and Cooperation, Hiroshima University \\ ${ }^{*}$ Corresponding author. Email: szhao@dlut.edu.cn
}

\begin{abstract}
Time use represents people's experience of daily lives and has various social meanings. However, existing time use researches in the context of university students have mainly focused on studying time and the association between studying and other activities has been neglected. Besides, existing researches are mainly based on cross-sectional data, which neglects the influences of temporal and individual variations. To tackle the above issues, this study first collected a weekly panel data (sample size: 1,057) of time use, and then built a multilevel utility-maximizing time use model with unobserved variations across individuals and over days of a week. The two types of unobserved variations are represented by introducing two additional error components into the time use model. The utility-maximizing principle reflects decision-making mechanisms. Time use models with decision-making mechanisms are useful to derive more scientifically sound insights than statistically-oriented models. The key findings are, (1) university students make decisions on studying time by considering the association with other activities and such an association is not homogeneous across activities; (2) students' physical and psychological conditions affect their time use decisions; (3) university students at different grade levels experience different dilemmas between studying and leisure times, between time use within campus and that outside campus; and (4) unobserved day-to-day variations and individual heterogeneity are influential.
\end{abstract}

Keywords: Time use; University students, Weekly panel data, China, Unobserved heterogeneity, Multilevel model, Simultaneous-equation model

\section{INTRODUCTION}

University students' time use management is important to realize the value of higher education [1]. While studying is the main task of students, students also spend their spare time on various other activities. Leisure activities allow students to relax, social activities allow students to learn how to communicate with the society, and students may also need to do some part-time job. Time use has various social meanings for university students [2]. However, existing researches on university students' time use have mainly focused on studying activity [3-4]. Sarath and Hudson [5] divided university students into two groups: campus-centered students and life-centered students, for evaluating time use of studying. In China, most of university students belong to campus-centered students. Such considerably enclosed campus life allows university students to save more time spent on schooling trips.
The main purpose of time use research is to understand how people make decisions on time use associated with various activities, conditional on available time. However, existing researches have ignored the influence of potential correlations between studying and other activities [6-7], and none of existing researches has explored university students' time use based on multi-day data. This study attempts to fill the above research gaps by answering the following three research questions.

Question 1: Whether are university students' decisions on time use of different activities independent of each other or not?

Question 2: What kinds of factors affect university students' various time use behaviors?

Question 3: What are the roles of unobserved factors in explaining university students' time use behaviors? 
For answering the above questions, this study collected a weekly panel data from students in a university of Dalian, China in 2017. Furthermore, a multilevel utility-maximizing time use model is developed, where both individual-related and day-to-day related unobserved factors are further incorporated.

Answering Question 1 has various implications about how to improve students' various abilities for their future lives by encouraging students to learn how to make tradeoff between various activities from a perspective of effective time use management. More time should be spent on studying on one hand, while physical exercises, leisure and social activities cannot be neglected on the other. Studying-life balance is important for university students. Learning how to make effective use of limited time during studying in universities is not only useful to improve their academic performance but also helpful for students to make a more successful life after graduation. Answering Question 2 is expected to provide various scientific insights about how to realize studying-life balance by considering various dilemmas in students' time use decisions from various angles. Finally, answering Question 3 has both statistical and policy values. This study deals with university students' time use over seven days of a week simultaneously. Such joint analysis needs to reflect not only day-to-day variations but also individual heterogeneity, which can be captured by introducing relevant error components into time use models. Revealing the influences of unobserved day-today variations and individual heterogeneity allows us to better understand university students' time use for future research, because it can tell us what kinds of additional sources of factors should be further investigated via new surveys.

In the remaining part of this paper, literature review is first presented, followed by descriptions about university students' time use survey and data collected. Next, the multilevel time use model is introduced. Furthermore, modeling estimation results are described and discussed. Finally, this study is concluded, together with a discussion about future research issues.

\section{LITERATURE REVIEW}

There are some significant gaps with respect to the research on university students' time use. Since this research aims to quantify the association of university students' time use between different activities and further identify influential factors, literature review is mainly given from a quantitative perspective.

\subsection{University students' time use behavior}

University students' time use is relatively flexible, in comparison with working population's time use [1]. A case study on the UK [8] found that students spend much less time on studying: only $13 \%$ of full-time four-year university freshmen spent 25 or more hours per week, while $41 \%$ just spent 10 hours or less. According to American Time Use Survey, university students in the USA spend 3.5 hours on educational activities, 4.0 hours on leisure and sports, 2.3 hours on working and related activities, and 1.4 hours on traveling. Thus, university students have more flexible time on other activities, such as leisure and part-time work. Bunn et al. [1] further analyzed university students' flexible time structures by associating with students' time management, by interviewing 27 students. For revealing the various social meanings of students' time, Liao et al. [2] classified university students' time into six categories, and demonstrated how these six types of time are managed and how they are embedded in social situations and social structure. Scheduled time is concluded to frame university students' other time uses. In other words, scheduled time constrains the other categories of time.

\subsection{Time use data and models}

Various time use data have been collected and accumulated, mainly in developed countries; however, most are cross-sectional data. Fosnacht et al. [7] estimated a latent class model about first-year university students' time use patterns and identified four patterns: balanced (69\%), involved (12\%: distinguished by time use on cocurricular activities and volunteering), partiers (14\%: differentiated by a substantial amount of time devoted to relaxing and socializing), and parents (5\%: spent substantial time caring for dependents and working for pay). Time use on weekdays is different from that on weekends and they may not be independent of each other; however, Fosnacht et al. [11] did not reveal any insights about weekly variations in students' time use.

Zhang et al. [9] developed a utility-maximizing time use model by explicitly incorporating the interdependency between weekdays and weekends and confirmed the modeling applicability using a weekly panel data, but with respect to general population. A weekly time use survey is useful to capture not only the variations of time use over a week across individuals, but also a work-leisure cycle [10]. Such weekly time use data needs to be pooled together for meaningful analyses. However, such data pooling usually results in potential collections across samples that are composed of both individuals and days. Unfortunately, existing researches have not well represented such correlations across samples. To accommodate such correlations, multilevel modeling approaches are useful to capture within-person changes and between-person differences, which history can be traced back to the 1980s [11]. In line with such a consideration, Taylor et al. [12] built a multilevel growth model with longitudinal data to analyze how students spend their leisure-time on physical activity; however, interactions between different activities are not taken into account. 
Etcheverry et al. [13] applied a path analysis model to examine time use and educational attainment of undergraduate students. Manwaring et al. [14] used a structural equation model (SEM) to investigate activitylevel engagement of university students in blended classes for gaining a holistic understanding of the influence of personal characteristics, course design, and student perceptions of the learning experience on in-themoment cognitive and emotional engagement. SEM and path analysis models are powerful and flexible to capture complicated cause-effect relationships among both observed and unobserved factors; however, they are after all statistically-oriented and cannot reflect the influence of behavioral decision-making mechanisms.

\subsection{Determinants of time use behaviors of university students}

\subsubsection{Gender}

Obvious gaps of time use between male and female have been identified, as female need to allocate more time on household labor, child care, and fewer hours on leisure and sleep [15]. However, university students, as a subgroup of the younger generation, are not involved in household labor, baby care and other issues. The distribution of female time and the types of activities they participate in are much more similar to their male peers when they are students [16]. However, Gershenson and Holt [17] found that there were gender gaps in high school students' homework time. Using a 7-day sleep log, Tsai and Li [18] compared college students' sleep patterns by gender and grade and found that female students went to bed and got up earlier and had longer sleep latency, and on weekdays, the freshmen got up earlier and had shorter sleep time than did the other students and seniors had the longest sleep latency.

\subsubsection{Social network}

Most relevant researches focus on the relationship between social network and grade point average. Taking Facebook as an example, Facebook users reported a lower GPA than non-users [19]. Additionally, Facebook users reported studying fewer hours per week than nonusers. Besides, there was a negative relation between time spent on Facebook and time spent on preparing for class [20]. The relation between academic performance and Facebook use is likely to be mitigated by multitasking [21]. The results showed that senior students spent significantly less time on Facebook and multitasking while using Facebook than other students.

\subsubsection{Comprehensive academic performance (CAP)}

Existing researches examined university students' time use of studying and its association with educational outcomes. Efforts and time spent on studying influenced learning performance [22]. However, the effects of time use on other daily activities are in dispute. Brint and Cantwell [3] argued that students' time uses of physical exercise and volunteering are associated with higher levels of academic conscientiousness, but not directly to higher CAP scores. Students' time use of entertainments show negative associations with CAP. Off-campus work showed a strong net association with lower CAP scores. These results provide evidence that CAP of university students is not independent of various daily activities. In reality, because of worse CAP, students may change their time use patterns by spending more time on studying to improve their CAP, while because of better CAP, students may also change their time use patterns by spending more time on leisure activities for relaxing; however, little is known in literature about how CAP affects time use.

\subsubsection{Physical and psychological conditions}

Different from university students' objective attributes, physical and psychological conditions may vary over time. In the case of longitudinal time use data like weekly panel data, variations of physical and psychological conditions may be key factors to capture within-person changes of university students' time use. However, relevant researches are limited. From the viewpoint of travel behavior, physical conditions are identified to affect individual time use of commute [23]. $\mathrm{T}$ High psychological conditions are positive with students' leisure-time on physical activity [12]. Focusing on Internet time use of students, Miao and $\mathrm{Na}$ [24] found that Internet time use correlates with physical and psychological sub-health and problematic Internet use is a risk factor for healthy development among adolescents.

\subsubsection{Other factors}

Etcheverry et al. [18] empirically confirmed the influences of individual and household attributes (including gender, age, father's occupation, father's education, years of university, number of credit hours), social psychological factors on undergraduate students' time uses (including attending classes, studying, time use in schools, and time spent on paid employment).

\section{SURVEY AND DATA}

\subsection{Survey design}

A questionnaire survey was designed, which includes two parts: one part is about basic individual attributes (age, gender, grade, social networking, CAP, living expenses, love relationship, daily physical conditions and daily psychological conditions) and the other is about daily time use over a week. 
Activity classification is fundamental to time use research, which directly affect the data structure of time allocation. Traditional time use surveys usually contain paid work, unpaid work, leisure, tertiary activities, transport, and sleeping, etc. As for university students, their activity classification should reflect their unique features. Except class activities, which are usually mandatory, university students' other activities are considerably flexible. For instance, university students usually live in dormitories within or nearby campuses, and as a result, they do not have to suffer from traffic congestion; and they are not forced to study in fixed areas. Because various facilities are scattered within and outside campuses, students still need to travel, as general residents make various daily trips. To reflect the above features of students' time use, campus daily activities are classified in terms of campus daily activity contents, activity zones and activity flexibility level. As most of campus trips in this survey are short-trips which are less than 15 minutes, in this paper time use of transport is temporarily ignored. As for leisure, this study defines leisure as self-arranged activity, except sleeping, studying, and trip making. Detailed contents of different activities are summarized in Table 1.

Table 1. Activities Classified in This Study.

\begin{tabular}{|l|l|}
\hline $\begin{array}{l}\text { Activity } \\
\text { location }\end{array}$ & Activity type \\
\hline \multirow{2}{*}{$\begin{array}{l}\text { Within campus: } \\
\text { Dormitory }\end{array}$} & Sleeping \\
\cline { 2 - 2 } & Self-study \\
\cline { 2 - 2 } Within campus: & Leisure \\
\hline Teaching area & Take lessons \\
\cline { 2 - 2 } & Self-study \\
\hline \multirow{2}{*}{ Outside campus } & Leisure \\
\cline { 2 - 2 } & Self-study, etc. \\
\hline
\end{tabular}

\subsection{Data collection}

The questionnaires were distributed to respondent students with the assistance of university staff in Dalian University of Technology. For each class, an administrator was selected for taking charge of reminding and monitoring students to fill out the questionnaires every day, as well as collecting the answered questionnaires. Both administrators and respondent students were paid with a small number of incentives. As a result, 162 undergraduate students participated in the survey, who came from four different grades. The data covered a whole week from June 5 to 11 in 2017. Excluding missing and invalid data, 151 undergraduates remained in this analysis. In other words, the sample size for this study is $1,057(=151$ persons $* 7$ days). Because each student provided time use data on seven days (five weekdays and two weekends), it is unrealistic to assume that all the 1,057 samples are independent. This is why the aforementioned multilevel modeling approach is adopted.

\subsection{Features of university students' time use}

Figure 1 shows the fluctuation of university students' time use of different activities in a week. Sleeping accounts for the highest proportion of time use, among all activities. Leisure in dormitory area is the second largest dominant activity, which average time is 4.4 hours per day. Outside campus activities show the least proportion of time use, which is less than $3 \%$ of the whole-time use. These results indicate that university students spend a majority of their time within campus. Such time use patterns are similar in other universities. The activity of taking lessons in teaching area shows a significant difference between weekdays and weekends, and the abrupt change drops nearly $80 \%$ on weekends. Such a difference is understandable. Time uses of selfarrange studying at different areas increase differently on weekend.

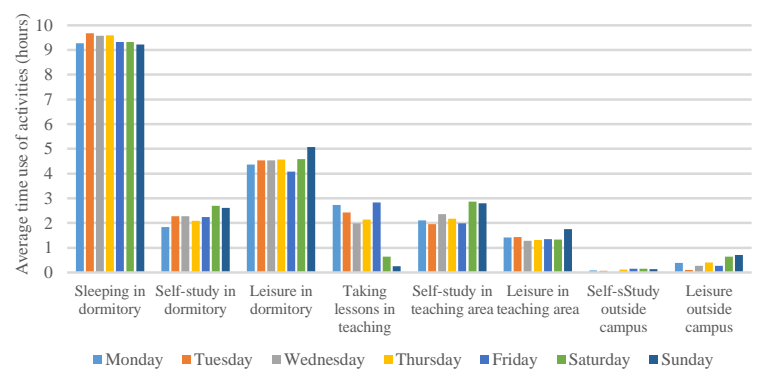

Figure 1 Average length of time spent on different activities in a week.

\section{MODEL}

\subsection{A utility-maximizing modeling framework}

Here, it is assumed that an individual $i$ (i.e., a student) maximize his/her utility $\left(u_{i d}\right)$ when deciding how to allocate the limited time to different activities in a certain day $d$. The utility $u_{i d}$ is measured as an additive-type function of activity $(k)$-specific utilities. For the above maximization, it is subject to the time constraint $T_{i d}$.

Maximize

$u_{i d}=\sum_{k} u_{i d}^{k}$

Subject to

$\sum_{k} t_{i d}^{k}=T_{i d}, k=1,2, \ldots, K$

$t_{i d}^{k} \geq 0, k=1,2, \ldots, K$

Here, $u_{i d}^{k}$ represents the time allocated by individual $i$ to activity $\mathrm{k}$ in day $\mathrm{d}$. 


\subsection{Definitions of utility functions}

First, the utility for each activity can be defined as follows, where $\alpha^{k}$ indicates an activity-specific constant term, $x_{i d q}^{k}$ refers to the qth explanatory variables for activity $\mathrm{k}$ and $\beta_{q}^{k}$ is its parameter, and $\varepsilon_{i d}^{k}$ represents an error term with respect to both $\mathrm{i}$ and $\mathrm{d}$.

$$
u_{i d}^{k}=\exp \left(\alpha^{k}+\sum_{q} \beta_{q}^{k} x_{i d q}^{k}+\varepsilon_{i d}^{k}\right) \ln \left(t_{i d}^{k}\right)
$$

Because the samples used in this study are composed of individual $\mathrm{n}$ and day $\mathrm{d}$, potential correlations across samples may be observed. To address such correlations, two more error components are further added: one $\left(\varepsilon_{i}\right)$ is specific to individual $i$ and the other $\left(\varepsilon_{d}\right)$ is specific to day $d$, as shown in equation (5). These two additional error components can also be used to capture unobserved heterogeneities with respect to individual $\mathrm{n}$ and day $\mathrm{d}$. Thus, the two additional error components play two types of roles, respectively. And $\mu \mathrm{k}$ and $\rho \mathrm{k}$ are the parameters illustrating the influences of the two types of unobserved heterogeneities on each activity.

$u_{i d}^{k}=\exp \left(\alpha^{k}+\sum_{q} \beta_{q}^{k} x_{i d q}^{k}+\mu^{k} \varepsilon_{i}+\rho^{k} \varepsilon_{d}+\varepsilon_{i d}^{k}\right) \ln \left(t_{i d}^{k}\right)$

\subsection{To derive time use functions}

The above utility-maximizing problem with a constraint can be resolved based on a Lagrangian approach is applied, where $\lambda \mathrm{id}$ is a Lagrange multiplier.

$L_{i d}=\sum_{k} u_{i d}^{k}+\lambda_{i d}\left(T_{i d}-\sum_{k} t_{i d}^{k}\right)$

Next, the first derivative is calculated as follows.

$\frac{\partial L_{i d}}{\partial t_{i d}^{k}}=\frac{\partial u_{i d}^{k}}{\partial t_{i d}^{k}}-\lambda_{i d}=0$

In this modeling framework, all the utility functions are assumed to be positive. Considering that utility is a relative concept, this assumption is not unrealistic and also necessary to guarantee the uniqueness of the derived time use models. The larger the positive utility, the more important the corresponding activity is for each university students' utility.

Solving equations (7) conditional on equation (2), the following time use function can be derived.

$t_{i d}^{k}=T_{i d} \frac{\exp \left(\alpha^{k}+\sum_{q} \beta_{q}^{k} x_{i d q}^{k}+\mu^{k} \varepsilon_{i}+\rho^{k} \varepsilon_{d}+\varepsilon_{i d}^{k}\right)}{\sum_{k^{\prime}} \exp \left(\alpha^{k^{\prime}}+\sum_{q} \beta_{q}^{k^{\prime}} x_{i d q}^{k^{\prime}}+\mu^{k^{\prime}} \varepsilon_{i}+\rho^{k^{\prime}} \varepsilon_{d}+\varepsilon_{i d}^{k^{\prime}}\right)}$

For ease of estimating equation (8), here, the following transformation (equation (9)) is adopted, where $\mathrm{k}_{0}$ is a reference activity.

$$
\begin{aligned}
\ln \left(t_{i d}^{k} / t_{i d}^{k_{0}}\right)= & \left(\alpha^{k}-\alpha^{k_{0}}\right)+\sum_{q}\left(\beta_{q}^{k} x_{i d q}^{k}-\beta_{q}^{k_{0}} x_{i d q}^{k_{0}}\right) \\
& +\left(\mu^{k}-\mu^{k_{0}}\right) \varepsilon_{i}+\left(\rho^{k}-\rho^{k_{0}}\right) \varepsilon_{d}+\left(\varepsilon_{i d}^{k}-\varepsilon_{i d}^{k_{0}}\right)
\end{aligned}
$$

Sleeping activity is selected as the reference activity, because sleeping activity is rigid demand of human every day and from the view of data, all the time values allocated to sleeping activity in this study are nonzero. As for explanatory variables, it was not possible to collect the information of activity-specific attributes. As a result, equation (9) can be re-written as follows.

$$
\ln \left(t_{i d}^{k} / t_{i d}^{k_{0}}\right)=\tilde{\alpha}^{k}+\sum_{q} \tilde{\beta}_{q}^{k} x_{i d q}^{k}+\tilde{\mu}^{k} \varepsilon_{i}+\tilde{\rho}^{k} \varepsilon_{d}+\tilde{\varepsilon}_{i d}^{k}
$$

Equation (10) is the final multilevel time use model for university students in this study. To estimate this model with three error terms, this study adopted Stata Version 15.0 by using its GSEM (generalized structural equation model) module. Details will be explained in the next section.

\section{ESTIMATION RESULTS AND DISCUSSION}

\subsection{Dependent and explanatory variables}

All the time use variables used in this study, as dependent variables, where sleeping in dormitory is treated as the reference activity for estimating the equation (10). Concretely speaking, there are seven logtransformed time variables (divided by the time allocated to sleeping in dormitory) with respect to self-studying in dormitory, leisure in dormitory, taking lessons in teaching area, self-studying in teaching area, leisure in teaching area, self-studying outside campus, and leisure outside campus.

Explanatory variables contain both day-invariant and day-varying variables (Table 2). The former includes six variables, which values are the same over the whole week, including gender, grade, social networking, CAP, living expenses, and love relationship. The latter (day-varying) variables latter include two variables: physical condition and psychological condition.

\subsection{Model estimation}

By incorporating explanatory variables and logtransformed dependent variables and, we draw the model structure of the equation (10), as shown in Figure 2, where $t_{0}$ indicates the time allocated to sleeping in dormitory, and $\ln \left(\mathrm{t}_{1} / \mathrm{t}_{0}\right), \ln \left(\mathrm{t}_{2} / \mathrm{t}_{0}\right), \ln \left(\mathrm{t}_{3} / \mathrm{t}_{0}\right), \ln \left(\mathrm{t}_{4} / \mathrm{t}_{0}\right), \ln$ $\left(\mathrm{t}_{5} / \mathrm{t}_{0}\right), \ln \left(\mathrm{t}_{6} / \mathrm{t}_{0}\right)$, and $\ln \left(\mathrm{t}_{7} / \mathrm{t}_{0}\right)$ are log-transformed time with respect to self-studying in dormitory, leisure in dormitory, taking lessons in teaching area, self-studying in teaching area, leisure in teaching area, self-studying outside campus, and leisure outside campus, respectively. As for the error terms $\left(\tilde{\varepsilon}_{i d}^{k}\right)$ in equation (10), they may not be independent of each other, because of the existence of 
potentially omitted variables common to time use on

Table 2. Explanatory Variables and Their Value Distributions.

\begin{tabular}{|c|c|c|c|c|c|c|c|c|}
\hline Variable & $\begin{array}{l}\text { Sample size } \\
\text { (ratio) }\end{array}$ & Variable type & Variable & $\begin{array}{c}\text { Sample } \\
\text { size (ratio) }\end{array}$ & $\begin{array}{c}\text { Variable } \\
\text { type }\end{array}$ & Variable & $\begin{array}{l}\text { Sample size } \\
\text { (ratio) }\end{array}$ & $\begin{array}{c}\text { Variable } \\
\text { type }\end{array}$ \\
\hline Gender & & Dummy value & $C A P$ & & $\begin{array}{l}\text { Ordinal } \\
\text { value }\end{array}$ & \multicolumn{2}{|c|}{ Physical condition } & Ordinal value \\
\hline Male & $111(73.5 \%)$ & 0 & Level A & $5(3.3 \%)$ & 1 & \multirow{3}{*}{$\begin{array}{l}\text { Healthy } \\
\text { Slightly } \\
\text { unhealthy } \\
\text { Unhealthy }\end{array}$} & $752(71.1 \%)$ & 1 \\
\hline Female & $40(26.5 \%)$ & 1 & Level B & $66(43.7 \%)$ & 2 & & $276(26.2 \%)$ & 2 \\
\hline Grade & & Ordinal value & Level C & $67(44.4 \%)$ & 3 & & $29(2.7 \%)$ & 3 \\
\hline Freshman & $35(23.2 \%)$ & 1 & Level D & $13(8.6 \%)$ & 4 & \multicolumn{2}{|c|}{ Psychological condition } & Ordinal value \\
\hline Sophomore & $48(31.8 \%)$ & 2 & Living expenses & & $\begin{array}{l}\text { Ordinal } \\
\text { value }\end{array}$ & $\begin{array}{l}\text { Happy } \\
\text { Comfort } \\
\text { Neutral } \\
\text { Anxious } \\
\text { Angry }\end{array}$ & $236(22.3 \%)$ & 1 \\
\hline Junior & $30(19.9 \%)$ & 3 & > $3000 \mathrm{RMB}$ & $3(2.0 \%)$ & 1 & \multirow{8}{*}{$\begin{array}{l}\text { Comfort } \\
\text { Neutral } \\
\text { Anxious } \\
\text { Angry }\end{array}$} & $259(24.5 \%)$ & 2 \\
\hline Senior & $38(25.1 \%)$ & 4 & 2000-3000 RMB & $38(25.2 \%)$ & 2 & & $279(26.4 \%)$ & 3 \\
\hline \multicolumn{2}{|c|}{ Social networking } & Ordinal value & 1000-2000 RMB & $93(61.6 \%)$ & 3 & & 267 (25.3\%) & 4 \\
\hline Very active & $4(2.7 \%)$ & 1 & $<1000 \mathrm{RMB}$ & 17 (11.2\%) & 4 & & $16(1.5 \%)$ & 5 \\
\hline Active & $22(14.5 \%)$ & 2 & Love relationship & & $\begin{array}{l}\text { Ordinal } \\
\text { value }\end{array}$ & & & \\
\hline Normal & $84(55.6 \%)$ & 3 & $\begin{array}{l}\text { In love within } \\
\text { daily space }\end{array}$ & 24 (15.9\%) & 1 & & & \\
\hline Inactive & $38(25.2 \%)$ & 4 & $\begin{array}{l}\text { Long distance } \\
\text { love }\end{array}$ & $19(12.6 \%)$ & 2 & & & \\
\hline Very inactive & $3(2.0 \%)$ & 5 & Single & $\begin{array}{r}108 \\
(71.5 \%)\end{array}$ & 3 & & & \\
\hline
\end{tabular}

Table 3. Estimation Results of College Students' Multilevel Time Use Model: Parameters of Explanatory Variables.

\begin{tabular}{|c|c|c|c|c|c|c|c|}
\hline Explanatory variables & $\begin{array}{l}\text { Self-study in } \\
\text { dormitory }\end{array}$ & $\begin{array}{l}\text { Leisure in } \\
\text { dormitory }\end{array}$ & $\begin{array}{c}\text { Taking } \\
\text { lessons in } \\
\text { teaching area }\end{array}$ & $\begin{array}{l}\text { Self-study in } \\
\text { teaching area }\end{array}$ & $\begin{array}{c}\text { Leisure in } \\
\text { teaching area }\end{array}$ & $\begin{array}{c}\text { Self-study } \\
\text { outside } \\
\text { campus }\end{array}$ & $\begin{array}{l}\text { Leisure } \\
\text { outside } \\
\text { campus }\end{array}$ \\
\hline \multicolumn{8}{|l|}{ Day-invariant variables } \\
\hline Gender & $-0.238(0.001)$ & $0.061(0.248)$ & $0.043(0.318)$ & $0.104(0.252)$ & $0.138(0.001)$ & $0.048(0.020)$ & $0.112(0.000)$ \\
\hline Grade & $0.130(0.000)$ & $0.061(0.004)$ & $-0.349(0.000)$ & $-0.140(0.000)$ & $0.044(0.011)$ & $0.029(0.001)$ & $0.112(0.000)$ \\
\hline Social networking & $0.058(0.211)$ & $-0.062(0.049)$ & $0.025(0.339)$ & $-0.004(0.938)$ & $-0.054(0.031)$ & $0.003(0.818)$ & $-0.016(0.413)$ \\
\hline CAP & $0.029(0.546)$ & $0.075(0.044)$ & $-0.006(0.845)$ & $-0.099(0.128)$ & $-0.037(0.194)$ & $-0.005(0.711)$ & $0.014(0.515)$ \\
\hline Living expenses & $-0.004(0.939)$ & $0.063(0.072)$ & $-0.051(0.071)$ & $-0.037(0.536)$ & $0.024(0.345)$ & $-0.008(0.548)$ & $-0.013(0.545)$ \\
\hline Love relationship & $0.016(0.738)$ & $-0.016(0.642)$ & $0.008(0.758)$ & $-0.087(0.137)$ & $-0.053(0.043)$ & $-0.017(0.182)$ & $0.003(0.864)$ \\
\hline \multicolumn{8}{|l|}{ Day-varying variables } \\
\hline Physical condition & $0.201(0.000)$ & $-0.038(0.284)$ & $0.019(0.594)$ & $-0.159(0.004)$ & $0.012(0.719)$ & $-0.018(0.293)$ & $-0.077(0.006)$ \\
\hline Psychological condition & $0.017(0.457)$ & $-0.012(0.464)$ & $-0.028(0.089)$ & $0.053(0.036)$ & $-0.015(0.339)$ & $0.012(0.118)$ & $-0.001(0.905)$ \\
\hline \multicolumn{8}{|l|}{$\begin{array}{l}\text { Additional error } \\
\text { components }\end{array}$} \\
\hline Day-specific & 1.000 & $0.682(0.000)$ & $-0.269(0.000)$ & $-1.350(0.000)$ & $-0.204(0.007)$ & $0.088(0.009)$ & $0.091(0.063)$ \\
\hline Individual-specific & 1.000 & $0.689(0.050)$ & $-4.962(0.003)$ & $1.252(0.018)$ & $0.412(0.164)$ & $0.266(0.090)$ & $1.004(0.011)$ \\
\hline Constant term & $-2.075(0.000)$ & $-1.043(0.000)$ & $-0.633(0.001)$ & $-0.605(0.054)$ & $-1.562(0.000)$ & $-2.319(0.000)$ & $-2.411(0.000)$ \\
\hline
\end{tabular}

Note: Parameter values in bond style: significant at $5 \%$ level; Parameter values in italic style: significant at $10 \%$ level.

different activities. Psychological factors related to time use preferences. It is ideal to accommodate correlations between all the seven error terms; however, it was difficult to obtain converged results. Instead, we assumed the correlation structure as shown in Figure 2, i.e., correlations between neighboring error terms are introduced. Using the GSEM module of Stata Version 15.0, the two additional error components ( $\varepsilon_{i}$ : individualspecific $(i=1,2, \ldots, 151) ; \varepsilon_{d}$ : day-specific $\left.(d=1,2, \ldots, 7)\right)$ are introduced as shown in the right side of Figure 2. The introduction of these two error components can also play a role in capturing correlations associated with time use 
behaviors. This also motivated us not to estimate the full matrices of all the correlations.

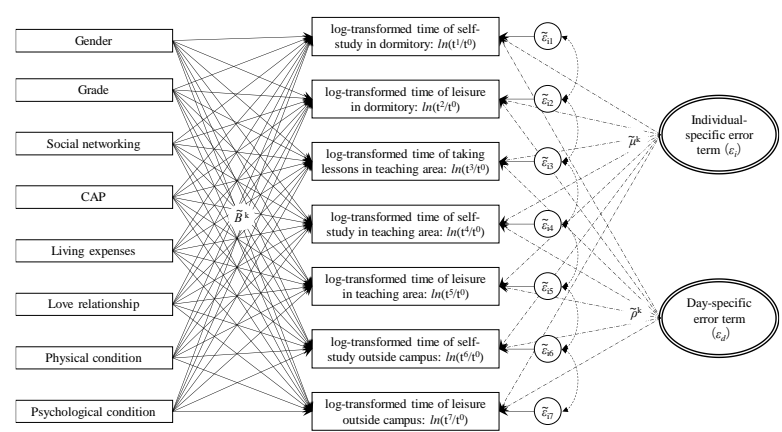

Figure 2 The structure of college students' time use model.

\subsection{Results of error terms/components}

Modeling results of the parameters of explanatory variables are shown in Table 3 and the variances of all error terms/components are displayed in Table 4.

Table 4. Variances of All Error Terms/Components.

\begin{tabular}{|l|r|}
\hline Variances & Parameters \\
\hline Error component specific to days & $\mathbf{0 . 1 0 5}$ \\
Error component specific to individuals & 0.005 \\
\hline Error term of the log-transformed time & \\
\hline Self-study in dormitory & $\mathbf{0 . 5 1 3}$ \\
Leisure in dormitory & $\mathbf{0 . 2 5 9}$ \\
Taking lessons in teaching area & $\mathbf{0 . 3 3 3}$ \\
Self-study in teaching area & $\mathbf{0 . 5 0 4}$ \\
Leisure in teaching area & $\mathbf{0 . 3 1 9}$ \\
Self-study outside campus & $\mathbf{0 . 0 7 9}$ \\
Leisure outside campus & $\mathbf{0 . 1 9 9}$ \\
\hline
\end{tabular}

Note: Parameter values in bond style: significant at $1 \%$ level.

Except the error component specific to individuals, all the other variances are statistically significant at $1 \%$ level. The insignificance of the error component specific to individuals implies that unobserved individual heterogeneity in this study does not matter to university students' time use decisions. On the other hand, the significant error component specific to the seven days of a week suggests that there exist unobserved factors associated with day-to-day variations of time uses, which should be further investigated in the future for bettering the representation of weekly time use decisions. As for the correlations introduced as in Figure 2, their values range from -0.066 to 0.028 : -0.056 between self-studying and leisure in dormitory, 0.026 between leisure in dormitory and taking lessons in teaching area, - -0.066 between taking lessons and self-studying in teaching area, -0.063 between self-studying and leisure in teaching area, 0.028 between leisure in teaching area and self-studying outside campus, and 0.023 between self-studying and leisure outside campus. Considering that correlations between error terms are usually caused by omitted (unobserved) factors, the existence of such factors lead to both negative and positive correlations between activities. All the above results support our hypothesis that university students' time use behaviors are not independent of each other. The large variations of the above parameters further suggest that the interactions among time use are not homogeneous among types of time use behaviors.

As for the two additional error components ( $\varepsilon i, \varepsilon d)$, their statistical significance should be judged by the relevant values in both Tables 3 and 4 . There are 14 relevant parameters, among which 10 are statistically significant at $1 \%$ or $5 \%$ level. This means that those unobserved (or omitted) factors related to individuals and days of a week surely matter to university students' time use decisions. These factors should be better surveyed in the future. Concerning their influences, both individualrelated and day-related unobserved factors tend to reduce time of taking lessons in teaching area, and day-related factors further reduce self-studying and leisure time in teaching area. Day-related unobserved factors are more likely to increase time spent on leisure in dormitory and activities outside campus, while individual-related unobserved factors tend to increase leisure in dormitory and outside campus. Note that the relevant parameters representing the influences of individual- and dayspecific error components on self-studying time in dormitory are fixed to be one during the model estimation.

\subsection{Results of explanatory variables}

The model estimation results indicate that different factors affect different time use behaviors in different ways.

Among the eight explanatory variables, only grade shows a consistently significant influence on all time use behaviors, but their influencing directions are not always the same. As the grade becomes higher, university students tend to increase time use in dormitory and outside campus as well as leisure time in teaching area, but reduce studying-related time use in teaching area.

Gender only affects self-studying time in dormitory area, leisure time in teaching area, and time use outside campus. Girl students tend to spend less time on selfstudying in dormitory, but more time on outside campus activities and more time on leisure in teaching area.

Social network is only influential to leisure time within campus. Students who are more active in social networking are more likely to spend more time on leisure activities within campus.

CAP is only influential to leisure time in dormitory. The higher the CAP score, the less time spent on leisure in dormitory, indicating that students with better studying performance spend more time on studying. 
Living expenses only affect leisure time in dormitory and time of taking lessons in teaching area. The higher the living expenses, the less time on leisure in dormitory and the more time on taking lessons in teaching area.

The smaller the value of love relationship, the closer the love relationship in terms of distance. Its influence is only observed with respect to leisure time in teaching area: Students having a boy or girl friend in a close distance are more likely to spend more time on leisure in teaching area.

Physical conditions are only relevant to decisions on self-studying time in dormitory, self-studying time in teaching area, and leisure time outside campus. Students with better physical conditions are more likely to spend less time on self-studying time in dormitory, but more time on self-studying time in teaching area and leisure time outside campus.

Psychological conditions are only influential to studying-related time use in teaching area. Students with better psychological conditions tend to spend less time on self-studying in teaching area, but take more lessons.

\subsection{More studying or more leisure: dilemma for university students}

Considering that the higher academic performance is associated with less leisure time in dormitory area, based on model estimation results, and generally speaking, more leisure time results in less time spent on studying, some dilemmas of university students in their decisions on different time use behaviors can be observed. Students at lower grades tend to spend their studying time in teaching area. Because students at lower grades normally have to take more lessons, as also evidenced by the modeling results, students' leisure life is clearly bothered, which may affect their QOL during studying. Comparing all the parameters of grade on time use, grade has a larger influence on leisure time outside campus (0.112) than on leisure time within campus $(0.061$ for that in dormitory area, 0.044 for that in teaching area). Living expenses contribute to the dilemma between studying and leisure time. Concerns about higher living expenses encourage to study more and play less.

One more type of dilemma can be observed with respect to time use within and outside campus. Girl students are more likely to participate in leisure activities outside campus and study more in teaching area (take more lessons and self-study longer), but study less in dormitory area. Because the parameter of gender for selfstudying time in dormitory area $(-0.238)$ is much larger than those for studying time in teaching area $(0.043$ for time of taking lessons and 0.104 for self-studying), it may be argued that the dilemma of between time use within and that outside campus for girl students is serious.
More active social networking seems to be good for both leisure and studying (i.e., self-studying in teaching area); however, the relevant parameters indicate that more active social networking surely reduce more time spent on studying in the sense that the parameters of social network are 0.058 for self-studying time in dormitory area, 0.025 for time of taking lessons in teaching area and -0.004 for self-studying in teaching area, respectively. For this dilemma between time use within campus and that outside campus, love relationship status seems not so relevant because it is only influential to leisure time in teaching area. Making a boy or girl friend seems to have little influence on studying time and is less likely to worsen the dilemma between time use within campus and that outside campus. Physical conditions contribute to the dilemma between time use within campus and that outside campus, while psychological conditions are only associate with within-campus time use.

Looking at all these positive and negative parameters of grade with respect to different time use behaviors, students at different grade levels suffer from different dilemma between studying and leisure time, between time use within campus and that outside campus.

\section{CONCLUSIONS}

University students need to make decisions on how to spend their limited time on different daily activities to improve their quality of university life. The decisionmaking of university students' time use involves serious dilemmas. Compared with working population, university students have more flexible time. Hence, an investigation of a single-day time use is unable to reflect university students' time use patterns in a relatively comprehensive way. This study first implemented a weekly panel data of university students' time use and then built a multilevel simultaneous-equation time use model to comprehensively represent university students' time use of all daily activities, rather than focusing on a single activity or a few activities. To incorporate the influence of unobserved factors on time use and reflect potential correlations across samples when using the weekly panel data, this study introduced two additional error components: individual-specific and day-specific.

The findings from this study can be summarized by presenting answers to the three research questions raised in Section 1.

Answers to "Question 1: Whether are university students' decisions on time use of different activities independent of each other or not?"

Our empirical analyses confirmed that various correlations were observed with respect to university students' time use decisions, most of which were negative. The correlations of different activities suggests that ignorance of a certain activity in time use analysis may lead to biased understanding of students' time use 
behaviors. This finding supports use of the utilitymaximizing modeling framework (equations (1) - (3)) consisting of not only all possible activities but also the constraint of available time. Correlations between activities are useful to consider studying-life balance for bettering students' lives from various angles: such as physical exercises, leisure and social activities.

Answers to "Question 2: What kinds of factors affect university students' various time use behaviors?"

The factors investigated in this paper are mostly significant, positively or negatively affecting different time use behaviors in different ways. This means that university students' time use decisions vary across students and across activities. These factors are influential to activity contents and/or activity locations, differently. CAP, love relationship, and psychological conditions influence time use decisions on a particular activity, social networking affects decisions on time use associated with activity locations, and gender, grade, and physical conditions are related to time use decisions in terms of both activity contents and activity locations. Results related to activity contents are conducive to improving the balance between studying and leisure. Results about activity locations are insightful to improving university students' health-related quality of life, such as mental issues and physical deterioration.

There are some opposite results from existing studies: 1) university students' studying time is not directly related to CAP, which is only influential to leisure time in dormitory; and 2) there was no direct relationship between university students' psychological conditions and leisure activities, where psychological conditions are only influential to studying-related time use in teaching area. Students with better psychological conditions tend to spend less time on self-studying in teaching area, but take more lessons. Furthermore, this study also revealed that university students at different grade levels suffer from different dilemmas between studying and leisure time, between time use within campus and that outside campus. Learning how to deal with these dilemmas will be beneficial to not only the improvement of academic performance, but also the future career life which usually involves more dilemmas.

Answers to "Question 3: What are the roles of unobserved factors in explaining university students' time use behaviors?"

This study confirmed that unobserved day-to-day variations and individual heterogeneity did matter to university students' time use decisions. First, this finding suggests that multi-day time use surveys are necessary to understand students' time use behaviors. The existence of day-to-day variations further suggests that modeling of day-to-day decision dynamics should be regarded as an important future research issue. Second, influences of unobserved day-to-day variations and individual heterogeneity varied across activities. This implies that activity-specific decision-making mechanisms should be better represented in the future. Third, the significant influence of unobserved individual heterogeneity suggests that analyses reflecting the above two points should not ignore differences across individuals. There probably exist various unobserved factors: both objective and subjective. Especially, one of the purposes of analyzing students' time use behaviors is to figure out how to encourage students to change their time use behaviors toward a better life. In other words, revealing the unobserved factors via surveys should not only focus on how to better fit those observed time use data, but also underscore a perspective of behavioral change.

Thus, answering the above three research questions has provided us several important insights into not only interdisciplinary research on university students' time use behaviors, but also cross-sectoral policymaking toward a better university life. The interdisciplinary perspective implies that university students' time use behaviors should be analyzed from a comprehensive and integrated way by making use of scientific knowledge from various disciplines for a better representation of time use decisions with respect to different activities, which may correspond to meeting different needs in their university life. The cross-sectoral perspective emphasizes that a better university life should not only be just a focus of educators, but also need the involvement of stakeholders in other sectors, which are associated with non-studying activities that are directly/indirectly influential to studying time. This study has presented a relatively holistic research framework that can capture university students' time use behaviors and influential factors.

\section{AUTHORS' CONTRIBUTIONS}

The authors confirm contribution to the paper as follows: study conception and design: Jingyao Li, Shengchuan Zhao, Junyi Zhang; data collection: Jingyao $\mathrm{Li}$; analysis and interpretation of results: Jingyao $\mathrm{Li}$, Shengchuan Zhao, Junyi Zhang; draft manuscript preparation: Jingyao Li. All authors reviewed the results and approved the final version of the manuscript.

\section{ACKNOWLEDGMENT}

This research is mainly supported by the National Natural Science Foundation of China (Project No. 51278087). The support is gratefully acknowledged.

\section{REFERENCES}

[1] Bunn, M., Bennett, A., Burke, P.J. (2018) In the anytime: Flexible time structures, student experience and temporal equity in higher education. Time \& Society, DOI: https://doi.org/10.1177/0961463X18787649 
[2] Liao, T.F., Beckman, J., Marzolph, E., Riederer, C., Sayler, J., Schmelkin, L. (2013) The social definition of time for university students. Time \& Society, 22(1):119-151.

[3] Brint, S., Cantwell, A.M. (2010) Undergraduate time use and academic outcomes: Results from the University of California Undergraduate Experience Survey 2006. Teachers College Record, 112: 24412470 .

[4] Mehta, N., Stinebrickner, R., Stinebrickner, T. (2019) Time-use and academic peer effects in college. Economic Inquiry, 57(1): 162-171.

[5] Sarath, A.N., Hudson, G.I. (2006) Academic performance of college students: Influence of time spent studying and working. Journal of Education for Business, 81(3):151-159.

[6] Bartolj, T. (2018) Does work harm academic performance of students? evidence using propensity score matching. Research in Higher Education, 59(4): 401-429.

[7] Fosnacht, K., McCormick, A.C., Lerma, R. (2018) First-year students' time use in college: A latent profile analysis. Research in Higher Education, 59(7): 958-978.

[8] Bennett, R. (2003) Determinants of undergraduate student dropout rates in a university business studies department. Journal of Further and Higher Education, 27(2): 123-141.

[9] Zhang, J., Timmermans, H.J.P., Fujiwara, A. (2007) A household time allocation model with behavioral interdependency between weekday and weekend. Selected Proceedings of the 11th World Conference on Transport Research, California, USA, June 2428 (CD-ROM).

[10] Jara-Díaz, S.R., Rosales-Salas, J. (2015) Understanding time use: Daily or weekly data? Transportation Research Part A, 76: 38-57.

[11] Steele, F. (2008) Multilevel models for longitudinal data. Journal of the Royal Statistical Society, Series A, 171:5-19.

[12] Taylor, I.M., Ntoumanis, N., Standage, M., Spray, C.M. (2010) Motivational predictors of physical education students' effort, exercise intentions, and leisure-time physical activity: A multilevel linear growth analysis. Journal of Sport \& Exercise Psychology, 32(1): 99-120.

[13] Etcheverry, E. J., Clifton, R. A., Roverts, L.W. (1993) Time use and education attainment: A study of undergraduate students. The Canadian Journal of Higher Education, 23(3):1-17.
[14] Manwaring, K.C., Larsen, R., Graham, C.R., Henrie, C.R., Halverson, L.R. (2017) Investigating student engagement in blended learning settings using experience sampling and structural equation modeling. The Internet and Higher Education, 35: $21-33$.

[15] Gershuny, J., Sullivan, O. (2003) Time use, gender, and public policy regimes. Social Politics,10(2): 205-228.

[16] Lloyd, C.B., Grant, M., Ritchie, A. (2010) Gender differences in time use among adolescents in developing countries: Implications of rising school enrollment rates. Journal of Research on Adolescence, 18(1): 99-120.

[17] Gershenson, S., Holt, S.B. (2015) Gender gaps in high school students' homework time. Educational Researcher, 44(8): 432-441.

[18] Tsai, L.L., Li, S.P. (2004) Sleep patterns in college students: Gender and grade differences. Journal of Psychosomatic Research, 56(2): 231-237.

[19] Kirschner, P.A., Karpinski, A.C. (2010) Facebook and academic performance. Computers in Human Behavior, 26(6): 1237-1245.

[20] Junco, R. (2012) Too much face and not enough books: The relationship between multiple indices of Facebook use and academic performance. Computers in Human Behavior, 28(1): 187-198.

[21] Junco, R., Cotton, S.R. (2012) No A 4 U: The relationship between multitasking and academic performance. Computers \& Education, 59(2): 505514.

[22] Gortner, L. A., Zulauf, C.R. (2000) Factors associated with academic time use and academic performance of college students: A recursive approach. Journal of College Student Development,41(5): 544-556.

[23] Lyons, G., Chatterjee, K. (2008) A human perspective on the daily commute: Costs, benefits and trade-offs. Transport Reviews, 28(2): 181-198.

[24] Miao, Z.Y., Na, L.U. (2015) Correlation between internet use time and physical and psychological subhealth among adolescents. Chinese Journal of Public Health, 31(12):1669-1671 (in Chinese). 